Revista Verde de Agroecologia e Desenvolvimento Sustentável

http://www.gvaa.com.br/revista/index.php/RVADS

ARTIGO CIENTÍFICO

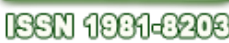

DOI: http://dx.doi.org/10.18378/rvads.v10i3.4607

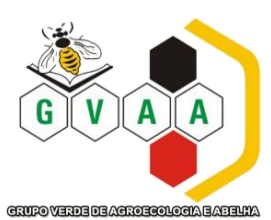

\title{
Variabilidade climática para o município de Patos, Paraíba, Brasil
}

\section{Climate variability for Patos city, Paraíba state, Brazil}

\author{
Hudson Ellen Alencar Menezes ${ }^{*}{ }^{1}$, Raimundo Mainar de Medeiros ${ }^{2}$, José Lucas Guilherme Santos $^{3}$, Tiago Silva Lima ${ }^{3}$
}

Resumo: O trabalho tem como objetivo avaliar as variabilidades climáticas no município de Patos - PB, enfocando tais variações como um meio para compreender futuras mudanças. Para realização deste trabalho utilizou-se dados de temperatura máxima do ar, umidade relativa do ar e totais pluviométricos mensais e anuais no período de 1994 a 2012 , da Estação Meteorológica do INMET na cidade de Patos. Como resultado pode-se afirmar que a temperatura do ar máxima anual demonstrou grande variação entre o período estudado, a temperatura máxima absoluta foi incrementada de $7 \%$ e a temperatura mínima absoluta sofreu uma redução de 10, podendo acarretar vários problemas socioeconômico, bem como, para a saúde humana. A partir dos dados, verifica-se, também, que a umidade relativa do ar está sendo incrementado ao longo da série estudada, fato que pode estar relacionado com o aumento da temperatura e consequentemente com uma maior evaporação das águas. Sobre os totais pluviométricos anuais, nota-se que os valores estão aumentando gradativamente, sendo que esse aumento pode estar relacionado com o aumento da temperatura, que faz com que se tenha uma maior evaporação e consequentemente uma maior precipitação.

Palavras-chave: Oscilações meteorológicas, Clima, Mudanças climáticas.

\begin{abstract}
The study aims to assess climate variability in Patos - PB city, focusing on such variations as a means to understand future changes. For this work we used maximum air temperature data, relative humidity and total monthly and annual rainfall from 1994 to 2012, the INMET Meteorological Station in Patos city. As a result one can be said that the temperature of maximum annual air showed great variation between the study period, the absolute maximum temperature was increased from $7 \%$ and the absolute minimum temperature was reduced by 10 , which may cause various socio-economic problems as well as to human health. From the data, it appears also that the relative air humidity being incremented along the series studied, which can be related to the temperature rise and consequently with a greater evaporation of water. On the annual rainfall totals, note that the values are gradually increasing, and this increase may be related to the temperature increase, which makes it has a higher evaporation and hence greater rainfall.
\end{abstract}

Keywords: Weather fluctuations, Climate, Climate changes.

\footnotetext{
*Autor para correspondência

Recebido para publicação em 28/08/2015; aprovado em 10/09/2015

${ }^{1}$ Doutor em Meteorologia, UFCG, Campina Grande - PB, Brasil, e-mail: hudson.ellen@ufcg.edu.br

${ }^{2}$ Doutor em Meteorologia, UFCG, Campina Grande - PB,Brasil, email:mainarmedeiros@ gmail.com

${ }^{3}$ Graduandos em Agronomia, UFCG, Pombal - PB, Brasil, e-mail: lucas1guilherme@ hotmail.com; lima_tiago92@outlook.com
} 


\section{INTRODUÇÃO}

O semiárido brasileiro é um dos maiores, mais populosos e mais úmidos do mundo, estando situado na porção central da região Nordeste abrangendo, no todo, ou em parte, 1.133 municípios, nove estados, em uma área de aproximadamente $969.589,4 \mathrm{~km}^{2}$ e 21 milhões de habitantes. Suas condições ecológicas típicas estão representadas nas ecorregiões, onde a vegetação predominante é a Caatinga. No Estado da Paraíba, 170 municípios, correspondendo a $85 \%$ da sua área, estão inseridos nesta região (BRASIL, 2005).

A variabilidade é um dos elementos mais conhecidos da dinâmica climática, o impacto produzido por essa variabilidade, mesmo dentro da normalidade pode ter representações significativas nas atividades humanas. Porém vale ressaltar que as anomalias podem desestruturar tanto o sistema ambiental, quanto o socioeconômico.

O Nordeste apresenta uma variabilidade espacial e intrasazonal, o que produz pelo menos três regimes de precipitação em três áreas distintas: uma área mais ao norte, onde as precipitações significativas ocorrem no bimestre março-abril; a faixa litorânea leste que se estende do Rio Grande do Norte ao sul da Bahia, com período chuvoso entre maio-julho; e uma terceira região que abrange grande parte da Bahia e sul do Piauí e Maranhão, cujos máximos de precipitação ocorrem de novembro a janeiro (MENEZES et al., 2003).

Nas últimas décadas, as alterações climáticas e suas consequências para a humanidade, tem sido uma das maiores preocupações de cientistas de todo o mundo. Principalmente no tocante aos fatores responsáveis pela variabilidade climática, que vêm se acentuando desde meados do século XX. As atividades humanas são, na visão de alguns pesquisadores, as responsáveis por parte destas mudanças. Entretanto, deve-se levar em consideração, uma possível variabilidade climática natural, uma vez que a magnitude do sinal associada a ela nos registros climáticos existentes, ainda não foi bem determinada (IPCC, 2001).

A visualização de tendências de mudanças climáticas em séries temporais meteorológicas, além de representar dados científicos importantes, é uma necessidade para estabelecer o efeito das mudanças climáticas sobre a dinâmica climática, fundamental para o planejamento futuro dos recursos hídricos, saúde humana e produção de alimentos (OBREGON; MARENGO, 2007).

Alguns cientistas questionam em diferentes graus a validade de estudos desenvolvidos em escala local para a compreensão da variabilidade global, porém são através dos estudos locais que se podem desenvolver estudos em escala regional e global (NUNES; LOMBARDO, 1995).

Nota-se, portanto que os estudos de séries meteorológicas, principalmente de dados extremos são essências para a compreensão da dinâmica climática, seja na escala local, regional ou global. Nestas séries, a temperatura do ar, a precipitação e a umidade relativa do ar tem papel principal. Sobre a temperatura e umidade do ar vale salientar que "[...] a temperatura, a umidade e a pressão atmosférica, que interagem na formação dos diferentes climas da Terra." (MENDONÇA; DANNI-
OLIVEIRA, 2005), ou seja, o conjunto destes três são os principais agentes formadores do clima.

Com isso objetivou-se avaliar as variabilidades climáticas no município de Patos, Paraíba, enfocando tais variações como um meio para compreender futuras mudanças.

\section{MATERIAIS E MÉTODOS}

O município de Patos localiza-se no Polígono das Secas, com uma área equivalente a $416 \mathrm{~km}^{2}$, está situado na zona fisiográfica do Sertão Paraibano, no centro do estado, na Microrregião da Depressão do Alto Piranhas, a $07^{\circ} 01^{\prime} 04^{\prime \prime}$ Latitude Sul e a $37^{\circ} 16^{\prime} 40^{\prime \prime}$ Longitude Oeste de Greenwich, a uma altitude de $240 \mathrm{~m}$ (Figura 1).

Segundo a classificação climática estabelecida por Köppen, o clima é do tipo Aw' (Quente e úmido com chuvas de verão a outono), caracterizado por possuir uma estação chuvosa que vai de janeiro a abril, com precipitações máximas nos meses de janeiro, fevereiro e março. A precipitação média está em torno dos $800 \mathrm{~mm}$.

Dadas às informações climatológicas e dinâmicas do nordeste brasileiro, o município, tem seu clima controlado pela variabilidade espacial e temporal da Zona de Convergência Intertropical (ZCIT), quando da sua atividade mais ao sul do equador, contribuição dos Vórtices Ciclônicos de altos níveis, deste que seu centro esteja no oceano, às contribuições dos efeitos locais, fatores que aumentam a cobertura de nuvens, a umidade relativa do ar e provocam chuvas de intensidade moderada a fraca em quase todos os meses do ano, sendo o fenômeno La Niña o principal fator para ocorrência de chuvas acima da média histórica provocando inundações, alagamento, enchentes, enxurradas e desmoronamento.

Figura 1. Localização do Município de Patos em relação ao Estado da Paraíba.

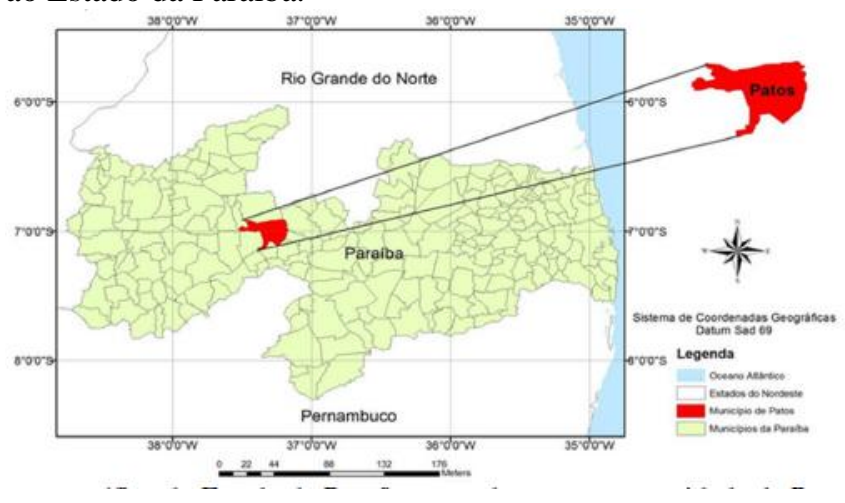

A topografia dos terrenos do município de Patos revela cotas situadas entre 240 metros a 580 metros. O seu relevo é predominantemente ondulado à suavemente ondulado, com declividade média à baixa, com exceção de áreas ao norte onde se localiza a serra de Carnaúba, ao sul nos serrotes de Espinho Branco e Forquilha, centro-oeste no serrote Serra Negra, noroeste nos serrotes Campo Alegre, Trapiá, e serra do Boqueirão, e a oeste nos serrotes Pitombeiras, do Caboclo e do Tamanduá. Nestas áreas a declividade é média à elevada.

Para se compreender a variabilidade climática existente no município de Patos - PB, trabalhou-se com a série meteorológica de temperatura máxima do ar, umidade relativa do ar e precipitação total mensal e anual, 
foi utilizado dado do período de 1991- 2010 por conterem menores falhas e boas consistências, os dados foram adquiridos da Estação Meteorológica de Patos localizada na latitude $07^{\circ} 01^{\prime}$ de latitude Sul e $37^{\circ} 16^{\prime}$ de longitude Oeste a uma altitude de $240 \mathrm{~m}$ acima do nível médio do mar. Pode-se afirmar que a estação já se encontra sendo ilhada pela urbanização vertical e pela falta de área verde, pois a paisagem está praticamente diferente das últimas décadas. Os dados de temperatura, umidade e precipitação foram disponibilizados pelo Instituto Nacional de Meteorologia (INMET).

As estatísticas utilizadas foram as bases para se gerar médias, desvio padrão, coeficientes de variâncias, máximos e mínimos valores absolutos para as séries de dados disponível para a área de estudo.

Nas plotagens dos dados e na elaboração dos gráficos utilizou-sedo software Microsoft Office Excel. Utilizou os dados observados nos horários sinóticos e aplicaram-se algumas estatísticas com a finalidade de obterem-se os resultados.

A apresentação dos resultados foram utilizados gráficos que para Ayoade (2010) "o clima de uma região é descrito com a ajuda de gráficos das variações sazonais nos valores dos elementos climáticos, usualmente a temperatura e a precipitação".

\section{RESULTADOS E DISCUSSÃO}

Tabela 1. Temperatura do ar máxima absoluta; Temperatura média máxima absoluta; Temperatura mínima absoluta e Temperatura média mínima mensal e anual em Patos - PB (1994-2012).

\begin{tabular}{|c|c|c|c|c|c|c|c|c|c|c|c|c|c|}
\hline Parâmetros/meses & Jan & Fev & Mar & Abr & Mai & Jun & Jul & Ago & Set & Out & Nov & Dez & Anual \\
\hline $\begin{array}{l}\text { Temperatura máxima } \\
\text { absoluta }\end{array}$ & 36,6 & 37,0 & 37,0 & 36,8 & 36,2 & 34,9 & 33,9 & 34,4 & 35,7 & 36,5 & 36,9 & 37,0 & 36,1 \\
\hline Média máxima absoluta & 34,8 & 34,2 & 33,7 & 33,4 & 32,9 & 32,3 & 32,4 & 33,3 & 34,8 & 35,9 & 36,3 & 36,0 & 34,2 \\
\hline $\begin{array}{l}\text { Temperatura mínima } \\
\text { absoluta }\end{array}$ & 20,0 & 20,7 & 20,5 & 20,5 & 18,9 & 18,9 & 19,2 & 17,9 & 18,9 & 19,5 & 18,4 & 20,7 & 19,5 \\
\hline Média mínima absoluta & 22,9 & 22,6 & 22,3 & 22,4 & 21,8 & 21,0 & 20,6 & 20,6 & 21,3 & 22,0 & 22,4 & 22,8 & 21,9 \\
\hline
\end{tabular}

Figura 2. Temperatura do ar máxima absoluta, média da máxima, temperatura mínima absoluta e média da mínima (a) temperatura máxima anual e linear em Patos - PB (1994-2012) (b).

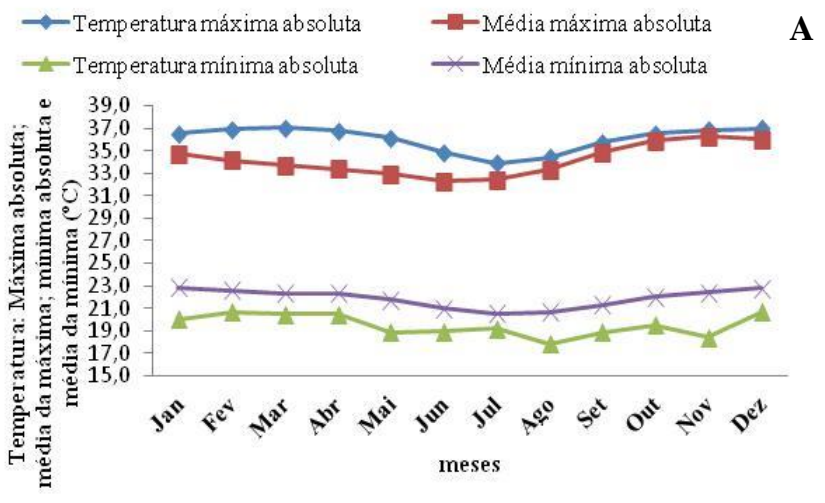

Analisando-se as médias das máxima e mínimas das temperaturas máximas ver-se que no mês de dezembro, fevereiro e março ocorrem as mais altas temperaturas, as menores flutuações forma registradas nos meses de junho, julho e agosto.

A Figura 3 demonstra a variabilidade da temperatura do ar máxima anual e sua tendência linear para Patos - PB no período de 1994-2012. Observando a Figura nota-se que os anos de 1998, 1999, 2003, 2010 e 2012 ocorreram temperaturas mais elevadas que a
O município de Patos apresenta elevadas temperaturas médias anuais, devido à influência da continentalidade e da média altitude. A temperatura é a medida, em graus Celsius, do aquecimento do ar pelos raios solares. Mede-se a temperatura do ar e não aquela exposta ao sol, portanto, os dados são aferidos dentro de abrigos meteorológicos (SANT'ANNA NETO; TOMMASELLI, 2009).

As séries da temperatura utilizadas foram relativamente homogêneas. No que se refere às temperaturas máximas absolutas e a média da máxima mensal e anual, já registrada em Patos, observar na Tabela 1, que a temperatura média máxima flutua entre $32,3{ }^{\circ} \mathrm{C}$ (junho) a $36,6^{\circ} \mathrm{C}$ (novembro) com uma taxa anual de $34,2^{\circ} \mathrm{C}$.

$\mathrm{Na}$ Figura 2, a variabilidade da temperatura máxima e mínima absolutas é as que apresentam maiores flutuações, com destaque para os anos de 1997 (dezembro, $37^{\circ} \mathrm{C}$ ), 1998 (março $37^{\circ} \mathrm{C}$ ), 1998 (fevereiro $37^{\circ} \mathrm{C}$ ), e no ano de 1994 no mês de março com $31,1^{\circ} \mathrm{C}$ e em janeiro de 1995 com 30,6 ${ }^{\circ} \mathrm{C}$. Ao longo do período analisado ocorre uma tendência de aumento nas temperaturas máximas anuais. Ressalta-se que tanto na flutuação das temperaturas máximas absolutas como nas mínimas absolutas as oscilações foram maiores no mês de março.
A

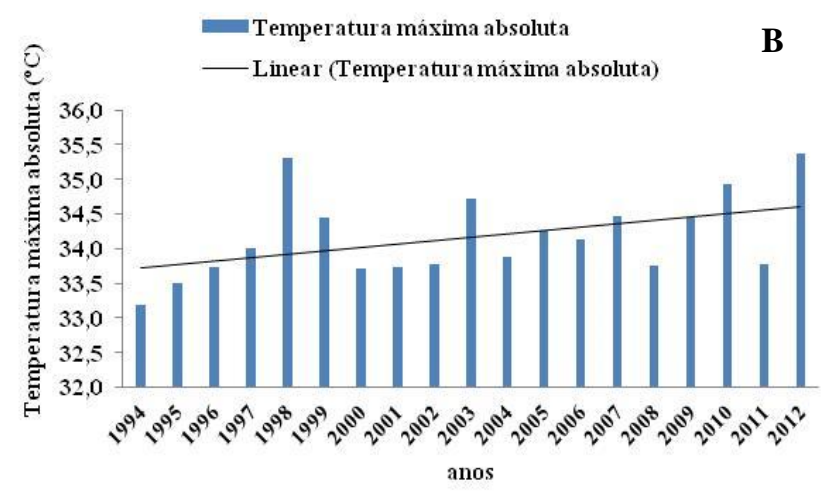

normalidade e os anos de 1994, 1995, 2008 e 2011registraram-se temperatura máxima abaixo da normalidade, estas oscilações podem estar relacionadas aos fenômenos de larga escala El Niño e La Niña e aos efeitos locais. A linha de tendência mostra um incremento na flutuabilidade das temperaturas máximas observadas dos anos estudado.

A umidade relativa do ar é a relação entre a quantidade de água existente no ar (umidade absoluta) e a 
quantidade máxima que poderia haver, na mesma temperatura (ponto de saturação).

A umidade relativa do ar apresenta-se com grandes oscilações diárias e mensais, conforme os padrões das regiões de transições entre semiárido e úmido e por outro lado devido à faixa de transição de telecomunicação com a Amazônia. A média da umidade relativa mínima varia entre aproximadamente 25 a $75 \%$, no decorrer do ano.

Ao analisar a umidade relativa do ar máximo e mínima absoluta e suas médias máximas e mínimas mensais e anuais em Patos - PB, observado na Tabela 2, a umidade relativa do ar média mínima oscila entre 43,2\% no mês de setembro a 44,1\% no mês de dezembro com uma taxa anual de 47,4\%.Na média mínima destacamos o ano de 1998 no mês de dezembro com 43,2\%. As oscilações das médias máximas fluem entre $55,4 \%$ no mês de outubro a $85,7 \%$ em abril com uma média anual de $69,8 \%$.

No período de registro (1994 - 2012), observou três anos que se considera como úmido (2008, 2009 e 2011) com taxas de umidade relativa maiores que $65 \%$, e os anos de 1998 e 1999 como valores de umidade relativa do ar próximo dos $50 \%$ sendo considerado de baixa umidade. Esse fenômeno pode estar relacionado com o aumento da temperatura média nas últimas décadas.

Tabela 2. Umidade relativa do ar máximo e mínima absoluta e sua média histórica mensal e anual no município de Patos - PB para o período de 1994 a 2012.

\begin{tabular}{|c|c|c|c|c|c|c|c|c|c|c|c|c|c|}
\hline Parâmetros/meses & Jan & Fev & Mar & Abr & Mai & Jun & Jul & Ago & Set & Out & Nov & Dez & Anual \\
\hline Umidade relativa máxima absoluta & 74,2 & 75,8 & 82,5 & 85,7 & 79,8 & 73,0 & 68,6 & 65,3 & 57,1 & 55,4 & 57,2 & 63,2 & 69,8 \\
\hline Média histórica & 59,6 & 64,3 & 68,7 & 69,5 & 65,8 & 63,6 & 58,6 & 54,0 & 49,6 & 48,7 & 49,5 & 52,0 & 58,6 \\
\hline Umidade relativa mínima absoluta & 48,8 & 48,5 & 51,6 & 49,9 & 49,4 & 48,2 & 51,4 & 47,2 & 44,1 & 43,2 & 43,3 & 43,2 & 47,4 \\
\hline
\end{tabular}

A Figura 3 demonstra a variabilidade da umidade relativa do ar máxima anual e sua tendência linear para o município de Patos, no período de 1994 a 2012. Com destaque os anos de 1994; 2005; 2006; 2007; 2008; 2009; 2010 e 2011 com maiores taxas de umidade relativa do ar e os anos de 1998 e 1999 como os de menores taxas de referido parâmetro em estudo.

Apesar da clara divisão da umidade relativa do ar em dois períodos bem distintos: um seco (agosto a dezembro) e um período úmido (janeiro a julho) observam-se na série que ocorreu uma elevação da umidade relativa, nos anos em estudo. O que, em parte, pode ser explicada pelo aumento da temperatura. Pode-se afirmar, portanto, que essa normalidade da variabilidade climática é típica da área semiárida, os quais possuem apenas duas estações, uma seca e outra chuvosa. A linha de tendência nos mostra aumentos significativos para os índices de umidade relativa do ar no período estudado.

Figura 3. Umidade relativa do ar anual e linear (a), Umidade relativa do ar máxima; média e mínima anual em Patos PB no período de 1994 a 12012, (b).

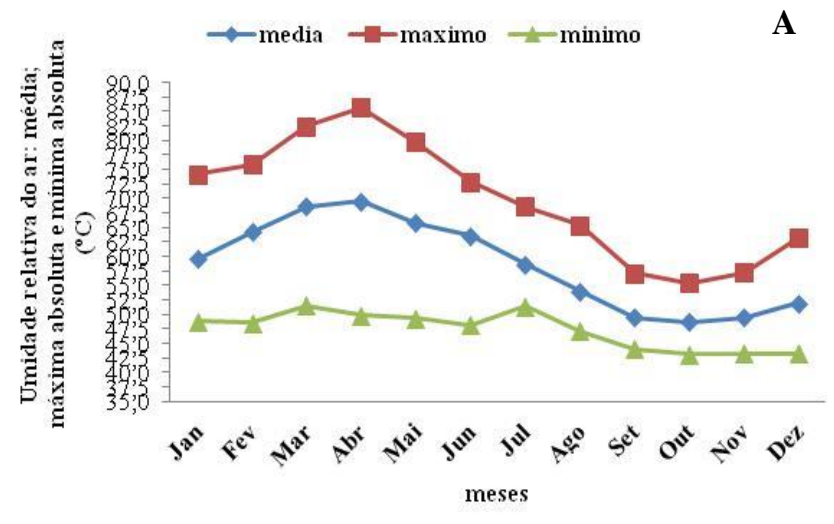

Como a umidade relativa do ar é proporcionalmente inversa à temperatura, ela é fator delimitante para ocorrência de chuvas com mais intensidades, nos últimos anos vem ocorrendo um aumento gradativo nestes valores. Esse índice pode estar relacionado com o aumento da temperatura $e$ consequentemente com uma maior evaporação das águas. Salienta-se que a umidade relativa do ar, nos meses secos já atingiu níveis críticos abaixo de $20 \%$, portanto, pode-se afirmar que ela vai influenciar mais ainda no cotidiano das pessoas, com agravamento dos problemas respiratórios, uns períodos secos mais secos e mais acentuados, com possibilidades de ocorrências de incêndios.

O total pluviométrico mensal é a soma total das chuvas ocorridas no decorrer de um mês, em milímetros. No período de 1994 a 2012 choveu em Patos - PB 826,1 $\mathrm{mm} /$ ano em média de forma irregular. Pode-se considerar a existência de duas estações: uma chuvosa e uma seca.

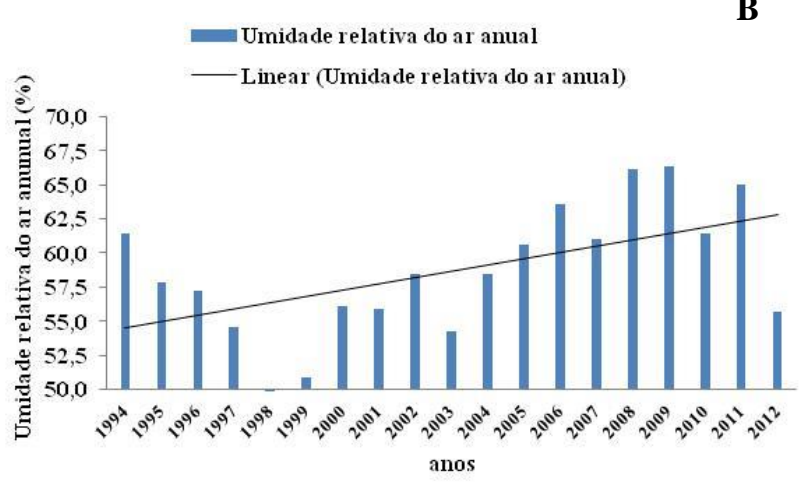

Essa estação chuvosa (janeiro a junho) é responsável por aproximadamente $89,48 \%$ das chuvas no município.

$\mathrm{Na}$ Figura 4a é possível observar que os totais pluviométricos anuais têm uma distribuição espaço temporais com irregularidade onde se destaca os anos de $1995 ; 1997 ; 1998 ; 2000 ; 2003 ; 2004 ; 2007 ; 2010$ e 2012com índices pluviométricos abaixo da normalidade já os anos de 1994; 1999; 2001; 2002; 2006; 2008 e 2009 ocorreram chuvas acima da normalidade. A linha de tendência mostra aumentos não muitos significativos nos índices pluviométricos para o período em estudo Esse fato pode estar relacionado com o aumento da temperatura do ar que vem ocorrendo nas últimas décadas. Esta variabilidade vai depender dos sistemas meteorológicos atuante na atmosfera, o que podem acarretar em chuvas acima ou abaixo da normalidade.

$\mathrm{Na}$ Figura 4b observa-se a oscilação da precipitação máxima absoluta, mínima absoluta e da 
média climatológica do período de 1994 a 2012, os maiores valores máximos de precipitações registrados ocorrem entre os meses de dezembro a maio, as mesmas flutuações são observadas neste período de tempo o que coincidem com a inicialização das chuvas de pré-estação e sua caracterização, nos meses de agosto a outubro a variabilidade dos índices pluviométricos máximos, mínimos e médios são insignificantes para a agricultura e represamento de água.

Estes resultados também foram encontrados por Medeiros (2013), para á área da bacia hidrográfica do rio Uruçuí Preto.

Figura 4. Totais pluviométricos anuais em Patos - PB período de 1994-2010 (a); Precipitação máxima; média da máxima, mínima da máxima e média mínima máxima anual em Patos - PB no período de 1994 a 2010.

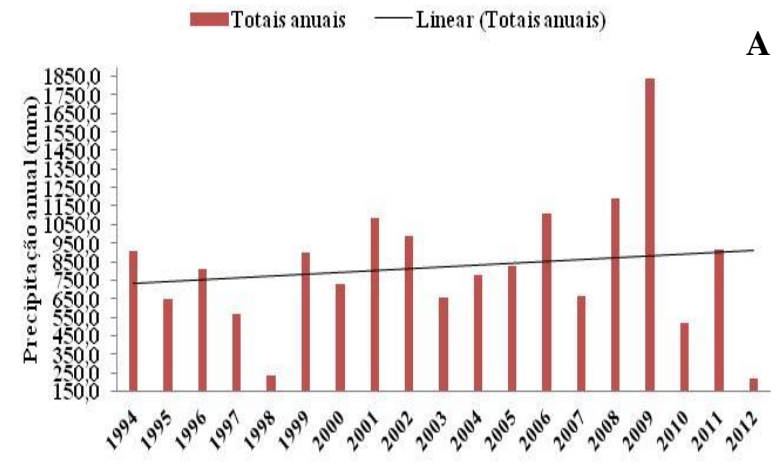

anos

\section{CONCLUSÕES}

Os resultados apresentados indicam possíveis variações climáticas na temperatura do ar, na umidade relativa do ar e na precipitação, apontando para uma tendência a condições mais quentes e chuvosas.

Ocorreu grande variação na temperatura do ar máxima anual entre o período estudado, a temperatura máxima absoluta foi incremento de $7 \%$ e a temperatura mínima absoluta sofreu uma redução de $10 \%$. Não se trata de um índice significativo, porém deve-se ficar alerta, pois essas reduções podem vim a causar vários problemas socioeconômico tais como: influência na perda de plantações, problemas no conforto térmico e até mesmo maior incidência de proliferação de doenças no ser humano e pragas na agricultura.

Para a precipitação total anual, demonstrou-se aumento gradativo nos seus índices nos últimos anos, esse aumento pode estar relacionado com o aumento da temperatura, que faz com que se tenha uma maior evaporação e uma maior precipitação como consequência.

\section{REFERÊNCIAS}

AYOADE, J. O. Introdução à climatologia para os trópicos. 13 ${ }^{\mathrm{a}}$ ed. Rio de Janeiro: Bertrand Brasil, 2010.

IBGE. Instituto Brasileiro de Geografia e Estatística. Disponível em:<http://www.ibge.gov.br $>$. Acesso em: ago. 2012.

INMET. Instituto Nacional de Meteorologia. Disponível em: <http://www.inmet.gov.br/portal/>. Acesso em: ago. 2012.

IPCC. Intergovernamental Panel on Climate Change: Climate Change 2001: The Scientific basis IPCC WG. Cambridge Univ. Press, 2001.

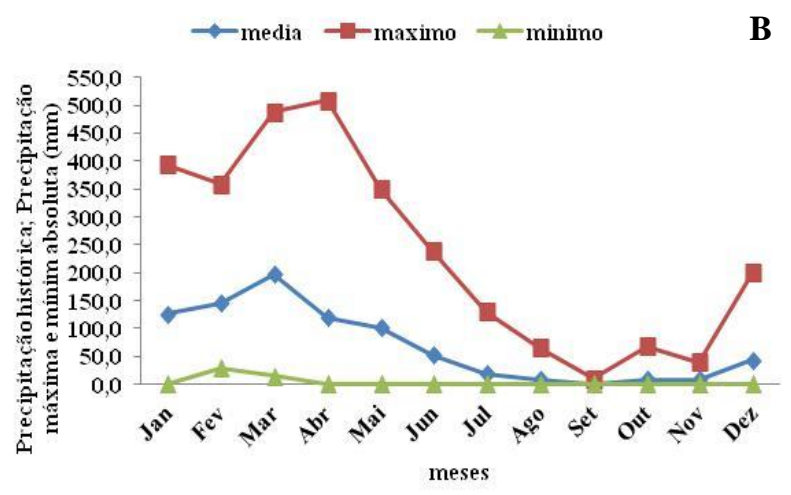

MEDEIROS, R. M. Estudo Agrometeorológico para o estado do Piauí. p.123. Divulgação avulsa. 2013.

MENDONÇA, F.; DANNI-OLIVEIRA, I. M. Climatologia: noções básicas e climas do Brasil. São Paulo: oficina de Textos, 2005.

MENEZES, H. E. A.; SILVA, R. M.; ALVES, L. M.; CAMARGO JÚNIOR, H. Verificação do prognóstico de precipitação sazonal simulada pelo modelo Eta climático para o Nordeste do Brasil. In: Congresso Brasileiro de Agrometeorologia, XIII, 2003, Santa Maria-RS. Anais: Santa Maria-RS: SBA, 2003, p. 999-1000.

MINISTÉRIO DA INTEGRAÇÃO NACIONAL. Relatório final. Grupo de trabalho interministerial para redelimitação do semi-árido nordestino e do polígono das secas. 2005. 118p.

NUNES, L. H.; LOMBARDO, M. A. A questão da variabilidade climática. Uma reflexão crítica. Revista IG. São Paulo, p. 21-31, 1995.

OBREGON, G., MARENGO J, A. 2007: Caracterização do clima do Século XX no Brasil: Tendências de chuvas e temperaturas médias e extremas. Relatório 2, MINISTÉRIO DO MEIOAMBIENTE - MMA, SECRETARIA DE BIODIVERSIDADE E FLORESTAS - SBF, DIRETORIADE CONSERVAÇÃO DA BIODIVERSIDADE - DCBio Mudanças Climáticas Globais e Efeitos sobre a Biodiversidade - Sub-projeto: Caracterização do clima atual e definição das alterações climáticas para o território brasileiro ao longo do Século XXI. Brasília, Fevereiro 2007.

SANT'ANNA NETO, J. L.; TOMASELLI, J. T. G. O Tempo e o Clima de Presidente Prudente. Presidente Prudente: FCT/Unesp, 2009.75p. 